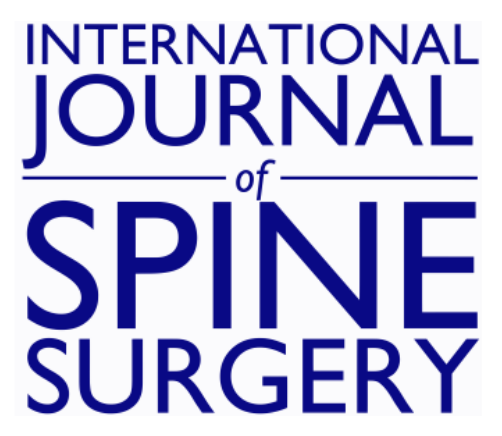

\title{
Spinal Osteoid Osteoma Revealed by Radiculopathy: Case Report and Literature Review
}

Aicha Ben Tekaya, Myriam Moalla, Mohamed Ben Salah, Olfa Saidane, Rawdha Tekaya, Khaled Hadhri, Ines Mahmoud and Leila Adbelmoula

Int J Spine Surg 2021, 14 (s4) S26-S32

doi: https://doi.org/10.14444/7161

http://ijssurgery.com/content/14/s4/S26

This information is current as of April 26, 2023.

Email Alerts Receive free email-alerts when new articles cite this article. Sign up at: http://ijssurgery.com/alerts 


\title{
Spinal Osteoid Osteoma Revealed by Radiculopathy: Case Report and Literature Review
}

\author{
AICHA BEN TEKAYA, MD, ${ }^{1,3}$ MYRIAM MOALLA, MD, ${ }^{1,3}$ MOHAMED BEN SALAH, PHD, $, 2,3$ OLFA \\ SAIDANE, PHD $, 1,3$ RAWDHA TEKAYA, PHD,${ }^{1,3}$ KHALED HADHRI, PHD ${ }^{2,3}$ INES MAHMOUD, PHD $, 1,3$ \\ LEILA ADBELMOULA, PHD ${ }^{1,3}$ \\ ${ }^{1}$ Rheumatology Department, Charles Nicolle Hospital, Tunis, Tunisia, ${ }^{2}$ Orthopedic Department, Charles Nicolle Hospital, Tunis, Tunisia, ${ }^{3}$ Faculty of medicine of \\ Tunis, University Tunis el Manar
}

\begin{abstract}
Osteoid osteoma $(\mathrm{OO})$ is a benign tumor that usually occurs in long bones of young males. We report a rare case of spinal OO in a 25-year-old woman, revealed by a sciatica. Spinal radiographs and computed tomography scan were normal, although performed at 6 months of symptom evolution. On magnetic resonance imaging, however, an important edema of the right transverse process of L5 vertebrae was depicted but was inconclusive. The diagnosis of OO was finally retained on a second computed tomography scan with thinner slices focused on the edematous area. The patient had an en-bloc excision of the tumor with complete regression of symptoms. Due to the atypical clinical presentation and the absence of common findings in imaging, the diagnosis was delayed by 12 months. Radiculopathy caused by spinal $\mathrm{OO}$ is a rare condition with no more than 30 cases reported in the literature. In fact, spinal OO usually presents with inflammatory back pain or painful scoliosis. This case emphasizes the importance of early suspicion and diagnostic interventions in the detection and treatment of $\mathrm{OO}$.
\end{abstract}

Lumbar Spine

Keywords: osteoma, osteoid, spine, radiculopathy, sciatica

\section{BACKGROUND}

Osteoid osteoma (OO) represents about $2 \%$ to $3 \%$ of all bone tumors. ${ }^{1}$ It usually occurs in the metaphysis and diaphysis of long bones. ${ }^{2}$ The spine is involved in up to $25 \%$ of OOs, particularly posterior elements of the lumbar segment. ${ }^{3}$ The clinical presentation varies depending on the location of the tumor.

We herein report the case of an OO of the lumbar spine revealed by sciatica. Given the atypical clinical presentation, the infrequency of such a location, and the imaging diagnosis difficulty, our case is worthy to report. The management of this entity was discussed based on a literature review of spinal OO revealed by radiculopathy. The search of articles was performed in Medline, Embase, Scopus, and Cochrane library databases. The following key words were used: ((“Osteoma, Osteoid") AND ("spine" OR "radiculopathy" OR "sciatica" OR "brachial neuralgia"). Key words referred to medical subject heading (MeSH).

\section{CASE PRESENTATION}

A 25-year-old woman presented with low back pain and right L5 sciatica evolving for 6 months.
She had no trauma or any relevant family or medical history. There was no history of fever or night sweats. She was experiencing morning stiffness and night pain that interfered with sleep. Pain was not relieved by paracetamol and opioids. Clinical examination revealed lumbar stiffness and no signs of neurological compromise except for the sciatica. Laboratory tests showed an erythrocyte sedimentation rate at $33 \mathrm{~mm}$ and $\mathrm{C}$-reactive protein level at $5.3 \mathrm{mg} / \mathrm{L}$.

All laboratory and imaging results, including plain radiography and a lumbar computed tomography (CT) scan, were initially normal.

Magnetic resonance imaging (MRI) performed 10 months after symptom onset revealed a bone marrow edema of the right L5 transverse process, centered by a linear low-intensity image on $\mathrm{T} 1$ and $\mathrm{T} 2$ weighting (Figures $1 \mathrm{~A}$ and $1 \mathrm{~B}$ ). However, no diagnosis could be established.

Since pain kept worsening despite analgesics, a second CT scan was performed after 12 months of symptom evolution, using thinner slices on the right transverse apophysis of L5. This CT scan showed a $4 \mathrm{~mm}$ cortico-subcortical osteolytic lesion, centered 


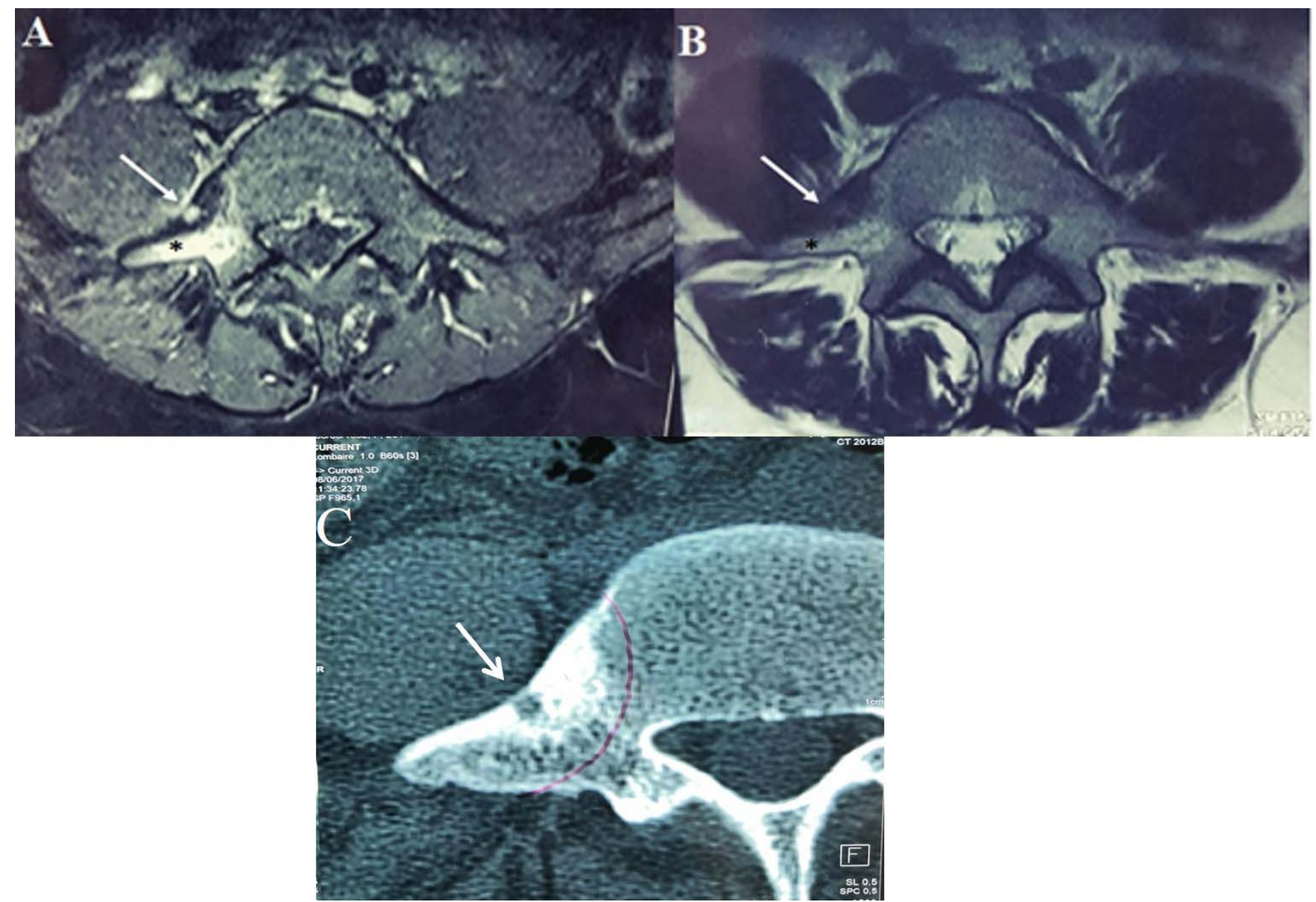

Figure 1. (A) Axial gadolinium-enhanced fat-suppressed T1-weighted magnetic resonance imaging showing the low-signal intensity lesion (white arrow), centered by a high-intensity round lesion which has strong enhancement, and edema in the surrounding bone marrow (*). (B) Axial T2-weighted magnetic resonance imaging of L5 vertebrae showing a low-signal intensity lesion of the right transverse process, with high-signal intensity peripherally $\left({ }^{*}\right)$ and heterogeneous signal intensity centrally (white arrow). (C) Computed tomography scan showing the lesion arising from right transverse process of L5 vertebrae, revealing the nidus (white arrow) surrounded by dense sclerotic bone in its periphery.

by a hyperdense millimetric nidus, surrounded by an area of osteosclerosis (Figure 1C). These findings led to a diagnosis of $\mathrm{OO}$ of the right transverse process of L5.

However, pain was only partially and temporarily relieved with aspirin. Therefore, the patient underwent an en-bloc excision with resection of the right L5 transverse process under general anesthesia. The patient was placed in the prone position on a radiolucent table. We used a posterior midline approach to expose the L5 transverse process under scopic control. An L5 transverse resection was performed with a bone surgical chisel with preservation of the articular capsule of the right L4-L5 articular mass. Histopathology of the intraoperative excised specimens (Figure 2A) confirmed the diagnosis of OO. Lumbar $\mathrm{x}$ rays and $\mathrm{CT}$ scan were performed the first postoperative day and confirmed the absence of residual nidus (Figures 2B and 2C).
Immediate pain relief was reported, and sciatica disappeared within the first postoperative hours, with a persistent remission at 30 months follow up. No complication associated with surgery occurred, and no muscle weakness was observed.

\section{DISCUSSION}

We report the case of a 25-year-old woman with an $\mathrm{OO}$ located in the $\mathrm{L} 5$ right transverse process revealed by right L5 sciatica. Our case is particular by the atypical clinical presentation, the tumor's location in the transverse process, and the occurrence in a female patient.

In fact, $\mathrm{OO}$ affects mainly males with a sex ratio of $3: 1 .^{4,5}$ Tumor distribution in spine regions varies among authors. For most authors, lumbar spine is the most commonly affected segment, followed by cervical and thoracic spine and sacrum. ${ }^{6}$ In a case series of 84 spinal OOs, posterior elements of the 


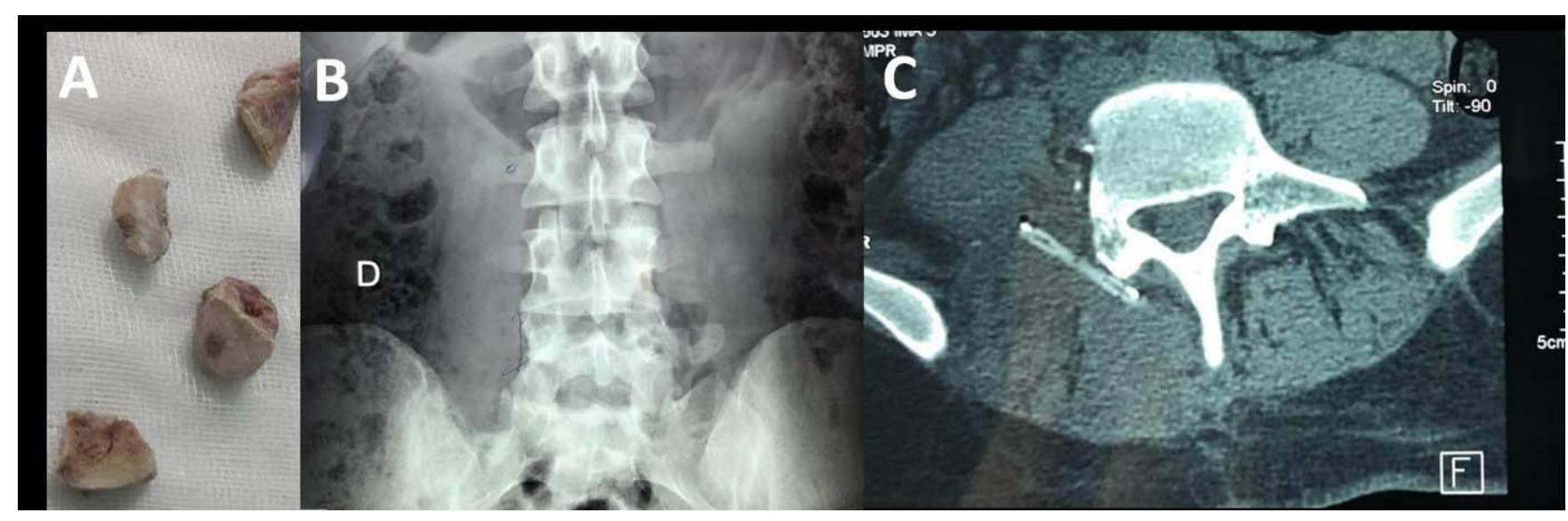

Figure 2. (A) Bone fragment of the en-bloc excision of right L5 transverse process containing the nidus surrounded by osteosclerosis. (B) Postoperative $x$ rays and (C) CT scan images of lumbar spine showing no residual tumor.

spine were 3 times more affected than vertebral body. ${ }^{5}$ Lamina and pedicles on the vertebral arch are most commonly affected, but cases involving the transverse processes have also been reported., ${ }^{5-10}$

The classic presentation of $\mathrm{OO}$ in a spinal location is a painful scoliosis or an isolated spinal night pain alleviated with the use of aspirin or nonsteroidal anti-inflammatory drugs. ${ }^{6}$ Radicular pain, as in our case, appears as a rare clinical picture in spinal OO. To date, there are 19 other reported cases of spinal $\mathrm{OO}$ revealed by radicular pain (Table). ${ }^{6,7,10-18}$ To our knowledge, only 2 cases of $\mathrm{OO}$ of the transverse process revealed by radicular pain have been reported. ${ }^{10,12}$

Despite advances in diagnostic technology, the average duration before establishing a diagnosis is 15 to 20 months. ${ }^{12}$ Depicting spinal OO on $\mathrm{x}$ rays is not an easy task, especially when $\mathrm{x}$ rays are performed in early stages of symptoms evolution, where radiographs are often normal. ${ }^{12}$ In more advanced conditions, we might identify the common aspect of $\mathrm{OO}$, which is an area of bone sclerosis surrounding a small radiolucent central region corresponding to the nidus. ${ }^{2}$ However, in our case, radiographs were still normal after a year of disease evolution. This might be explained by the complex anatomy of the spine and the small size of the tumor, making the osteolytic lesion almost not visible on plain radiographs. ${ }^{19}$

MRI and CT are more sensitive than $\mathrm{x}$ rays for detecting soft tissue and bone marrow abnormalities adjacent to OO. ${ }^{19}$ However, in our case, MRI could not individualize the nidus, which was drowned in edema and osteosclerosis. Moreover, when the nidus is not identified, images of perilesional edema provided with MRI might be confused with an aggressive tumor-evoking aspect or with images of bone infection. ${ }^{20}$ In such cases, CT scan might redress the diagnosis. CT scan remains the most specific diagnostic imaging modality to analyze the nidus with the varying degrees of perinidal sclerosis. $^{20,21}$

Our case emphasizes the value of CT scan in the diagnosis of OO by giving thin cross-sectional images of the suspected area. In a case reported by Ono et $\mathrm{al}^{21}$, CT with 1-mm slices showed the nidus with a clear, round osteolytic lesion ossification inside, leading to a diagnosis of $\mathrm{OO}$, although the nidus had been overlooked in CT with 5 -mm slices because of its small size, and the patient was diagnosed with lumbar spondylolysis on initial MRI and CT.

Spinal OO can be treated either with surgical intervention or minimally invasive interventions. ${ }^{5}$ Surgical options include intralesional curettage or marginal or en-bloc excision. ${ }^{4,5}$ Minimally invasive interventions consist of radiofrequency thermoablation (RFA) or CT-guided core excision. ${ }^{22}$

RFA has been proven to be effective and safe, with less complications and shorter hospitalization than surgical treatment. ${ }^{22,23}$ However, RFA cannot be performed safely if there is neurological impairment, if cortical bone around CT lesions is not intact, or if the cerebrospinal fluid between the lesion and nerve root or spinal cord is not sufficient $(<1 \mathrm{~mm})$ on MRI. In cases like ours in which osseous tumor infiltration produces radicular nerve root irritation and radicular symptoms, wide surgical excision of the tumor and surrounding tissue is the treatment of choice. ${ }^{12,22,23}$ Moreover, en-bloc excision is a guarantor of lower risk of recurrence than piecemeal excision, curettage, and 
Tekaya et al.

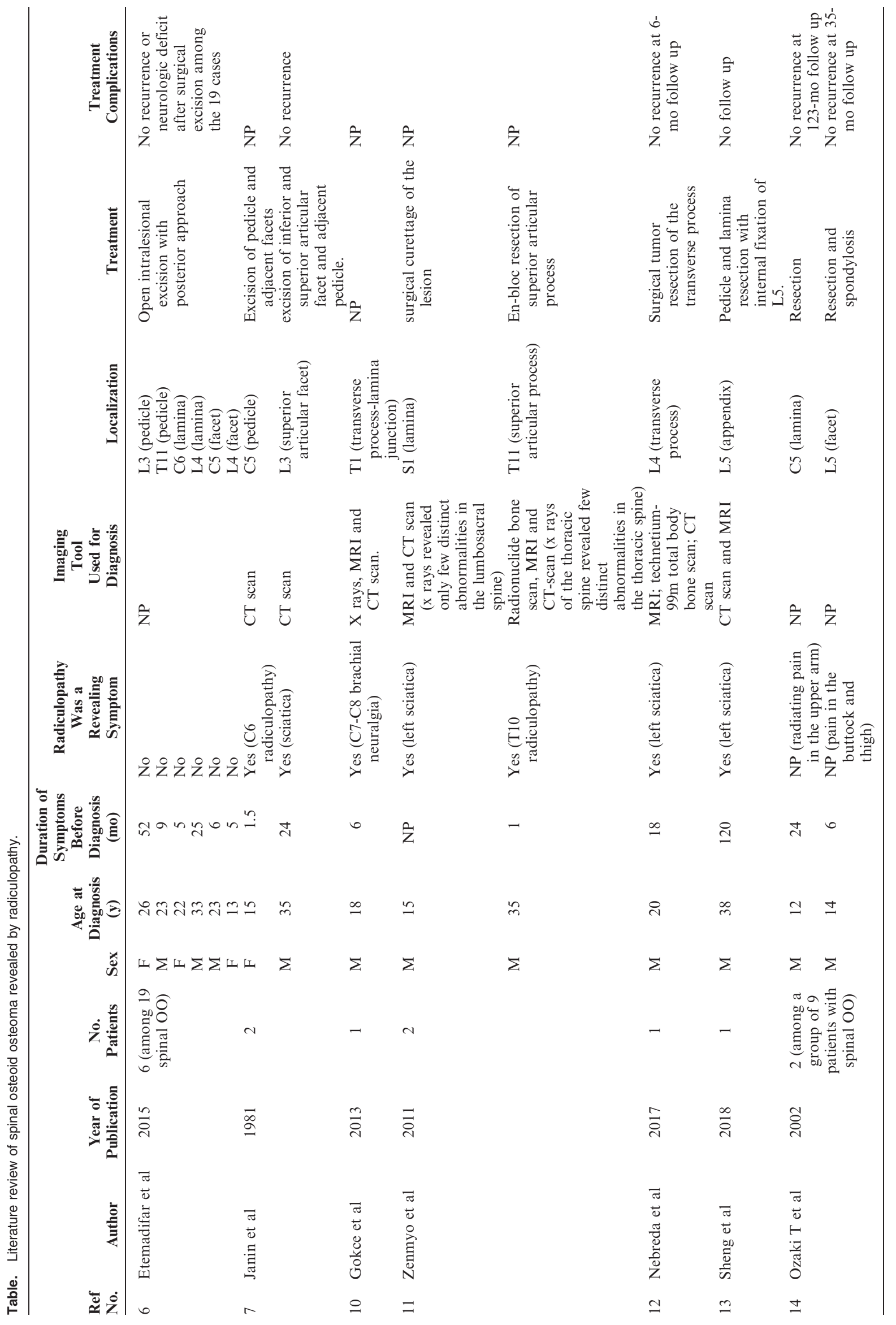


Spinal Osteoid Osteoma Revealed by Radicular Pain

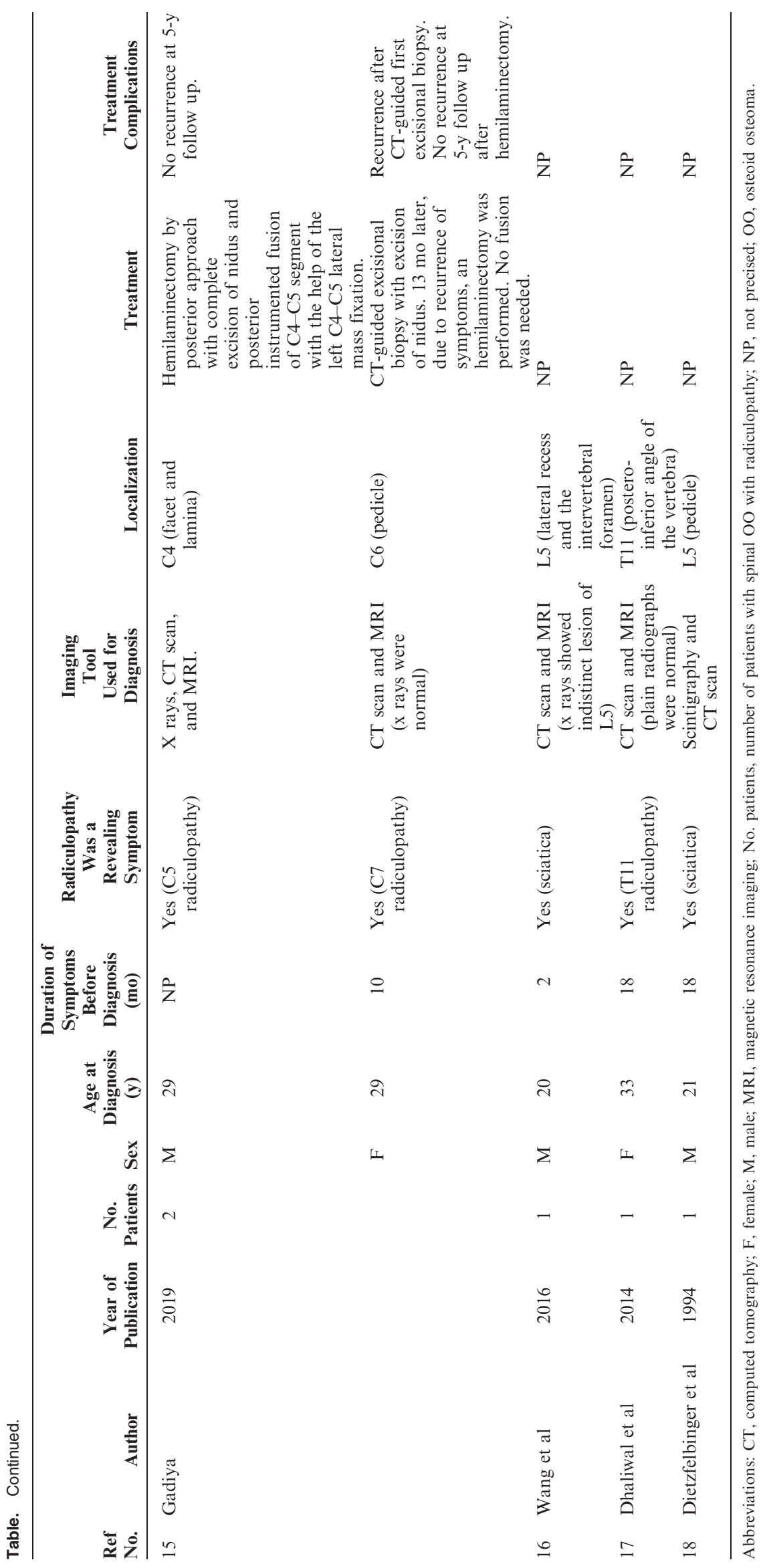


RFA, since it leads to a complete removal of the nidus. $^{5,22}$

\section{CONCLUSIONS}

Radiculopathy is an uncommon clinical presentation in spinal OO that might be responsible for a prevalent diagnosis delay. Although not frequent, OO should be suspected in all young patients with inflammatory spinal symptoms even if $\mathrm{x}$ rays are normal.

Our case emphasizes the better accuracy of CT scan in detecting OO compared to MRI and $\mathrm{x}$ rays. In case of any doubt, it is necessary to resort to the thin section CT scan which could be guided with MRI. Treatment depends on location. Surgical removal can be performed safely in spinal OO within posterior elements. RFA can be a good alternative if there is no neurological impairment.

\section{KEY MESSAGES}

- Although radicular pain revealing spinal osteoid osteomas is clinically uncommon, the diagnosis should always be suspected and imaging findings interpreted with caution especially in young patient with inflammatory and chronic symptoms.

- Osteoid osteoma may display misleading imaging findings, and it can be difficult to differentiate osteoid osteoma from other conditions such as infection or other benign or malignant tumors.

- To make the correct diagnosis, it is necessary to identify the nidus, and it is important to be familiar with the radiologic findings of osteoid osteoma and its mimics.

\section{REFERENCES}

1. Jordan RW, Koç T, Chapman AW, Taylor HP. Osteoid osteoma of the foot and ankle - a systematic review. Foot Ankle Surg. 2015;21(4):228-234. doi:10.1016/j.fas.2015.04.005

2. Iyer RS, Chapman T, Chew FS. Pediatric bone imaging: diagnostic imaging of osteoid osteoma. AJR Am J Roentgenol. 2012;198(5):1039. doi:10.2214/AJR.10.7313

3.Pinto $\mathrm{CH}$, Taminiau AH, Vanderschueren GM, et al. Technical considerations in CT-guided radiofrequency thermal ablation of osteoid osteoma: tricks of the trade. AJR Am J Roentgenol. 2002;179(6):1633-1642. doi:10.2214/ajr.179.6. 1791633

4. Gasbarrini A, Cappuccio M, Bandiera S, Amendola L, van Urk P, Boriani S. Osteoid osteoma of the mobile spine: surgical outcomes in 81 patients. Spine. 2011;36(24):2089-2093. doi:10.1097/BRS.0b013e3181ffeb5e

5. Quraishi NA, Boriani S, Sabou S, et al. A multicenter cohort study of spinal osteoid osteomas: results of surgical treatment and analysis of local recurrence. Spine $J$. 2017;17(3):401-408. doi:10.1016/j.spinee.2016.10.010

6. Etemadifar MR, Hadi A. Clinical findings and results of surgical resection in 19 cases of spinal osteoid osteoma. Asian Spine J. 2015;9(3):386-393. doi:10.4184/asj.2015.9.3.386

7. Janin Y, Epstein JA, Carras R, Khan A. Osteoid osteomas and osteoblastomas of the spine. Neurosurgery. 1981;8(1):31-8. doi:10.1227/00006123-198101000-00007

8. Banzo I, Hernandez-Allende R, Quirce R, et al. Bone SPECT in an osteoid osteoma of transverse process of first lumbar vertebra. Clin Nucl Med. 2005;30(1):28-29. doi:10.1097/ 00003072-200501000-00009

9. Biswas D, Mal RK. Dysphagia secondary to osteoid osteoma of the transverse process of the second cervical vertebra. Dysphagia. 2006;22(1):73-75. doi:10.1007/s00455006-9035-6

10. Gokce E, Ayan E, Çelikyay F, et al. Radiological imaging findings of a case with vertebral osteoid osteoma leading to brachial neuralgia. J Clin Imaging Sci. 2013;3(1):54. doi:10.4103/2156-7514.122324

11. Zenmyo M, Yamamoto T, Ishidou Y, Komiya S, Ijiri K. Osteoid osteoma near the intervertebral foramen may induce radiculopathy through tumorous inflammation. Diagn Pathol. 2011;6(1):10. doi:10.1186/1746-1596-6-10

12.Nebreda CL, Vallejo R, Mayoral-Rojals V, Ojeda A. Osteoid osteoma: benign osteoblastic tumor of the lumbar L4 transverse process associated with radicular pain: a case report. Pain Pract. 2017;18(1):118-122. doi:10.1111/papr.12577

13.Sheng X, Cai G, Gong X, et al. A misdiagnosed case of osteoid osteoma of L5. J Back Musculoskelet. 2018;31(1):215219. doi:10.3233/BMR-170850

14. Ozaki T, Liljenqvist U, Hillmann A, et al. Osteoid osteoma and osteoblastoma of the spine: experiences with 22 patients. Clin Orthop Relat Res. 2002 Apr;(397):394-402. doi: 10.1097/00003086-200204000-00046.

15. Gadiya A, Shah K, Patel P, et al. Osteoid osteoma of cervical spine: a case report and review of literature. J Orthop Case Rep. 2019;9(1):78-81. doi:10.13107/jocr.2250-0685.1318

16. Wang G, Kang Y, Lv G, Li Y, Wang B. Osteoid osteoma leading to sciatica. Spine J. 2016;16(5):e315. doi:10.1016/j. spinee.2015.11.038

17. Dhaliwal HS, Makkar DS, Gowda KK. A curious case of abdominal pain relieved by aspirin. Gastroenterology. 2014;147(4):745-748. doi:10.1053/j.gastro.2014.04.057

18. Dietzfelbinger T, Doerr M, Oberst G, et al. Osteoidosteom als Ursache einer therapieresistenten Lumboischialgie. Article in German. Schmerz. 1994;8(X):246-248. doi:10.1007/ BF02527894

19. Harish S, Saifuddin A. Imaging features of spinal osteoid osteoma with emphasis on MRI findings. Eur Radiol. 2005;15(12):2396-2403. doi:10.1007/s00330-005-2816-8

20. Hosalkar HS, Garg S, Moroz L, et al. The diagnostic accuracy of MRI versus CT imaging for osteoid osteoma in children. Clin Orthop Relat Res. 2005 Apr;(433):171-7. doi: 10. 1097/01.blo.0000151426.55933.be. Erratum in: Clin Orthop Relat Res. 2005 Jul;(436):286. PMID: 15805954.

21. Ono T, Sakamoto A, Jono O, Shimizu A. Osteoid 
osteoma can occur at the pars interarticularis of the lumbar spine, leading to misdiagnosis of lumbar spondylolysis. Am J Case Rep. 2018;26 (19) :207-213. doi:10.12659/ajcr.907438

22. Wang B, Han SB, Jiang L, et al. Percutaneous radiofrequency ablation for spinal osteoid osteoma and osteoblastoma. Eur Spine J. 2017;26(7):1884-1892. doi:10. 1007/s00586-017-5080-0

23. Yu X, Wang B, Yang S, et al. Percutaneous radiofrequency ablation versus open surgical resection for spinal osteoid osteoma. Spine J. 2019;19(3):509-515. doi:10.1016/j. spinee.2018.07.013

Disclosures and COI: All authors declare that they have participated in the design and analysis of the paper and that they have approved the final version. Additionally, there are no conflicts of interest in connection with this paper. We certify that the manuscript is original, not published previously, and not under concurrent consideration elsewhere.

Corresponding Author: Moalla Myriam, Rheumatology Department, Charles Nicolle Hospital, Djebel Lakhdher Street, Bab Saadoun, Tunis, Tunisia. Phone: +216 216900 44; Email: myriammoalla@live.fr.

Published 11 February 2021

This manuscript is generously published free of charge by ISASS, the International Society for the Advancement of Spine Surgery. Copyright (c) 2020 ISASS. To see more or order reprints or permissions, see http://ijssurgery.com. 